\title{
DIFFUSION SOLDERING
}

\section{A NEW LOW TEMPERATURE PROCESS FOR JOINING CARAT GOLD JEWELLERY}

\author{
G. Humpston, D.M. Jacobson \& S.P.S. Sangha \\ Hirst Research Centre \\ GEC-Marconi Ltd. \\ Wembley, United Kingdom
}

Diffusion soldering is a hybrid of diffusion bonding and soldering. The principle of the process is to run a minute volume of solder into a joint between components that are pressed together and to solidify the solder by conversion to high melting point phases through isothermal reaction with the substrates. Thereafter the joint will not remelt unless heated to the temperature at which the high melting point phases melt. Tin can be used to make diffusion soldered joints between components of pure gold.

The objctive of the present study was to evaluate tin as a diffusion solder for joining items of 18 carat golds, representative of alloys widely used in the fabrication of jewellery. The permissible range of the process parameters have been identified and a process specification has been developed. Joints can be made by heating to $450^{\circ} \mathrm{C}$, which is substantially lower than the temperature needed for brazing of jewellery using conventional carat filler alloys. The resulting joints are colour matched and have mechanical properties that are likely to be adequate for jewellery applications. Diffusion soldering with tin has also been applied successfully to join 22 carat jewellery and the new jewellery alloy of 990 gold. 


\section{INTRODUCTION}

Gold jewellery is traditionally manufactured by brazing together a number of intricate components, fabricated by casting or mechanical working, using the so-called carat gold solders. For 18 carat gold jewellery, these solders are alloys with a working temperature in the range 700 to $820^{\circ} \mathrm{C}$ [1]. The joining operations are normally carried out in a belt furnace or with the aid of a torch. Fluxes are used to promote wetting of the components by the filler metal and thereby improve flow.

The high temperatures involved in this type of joining process are detrimental to the mechanical robustness of jewellery because carat gold alloys anneal and soften rapidly when heated above about $450^{\circ} \mathrm{C}$. Figure 1 shows how the mechanical properties, in this case hardness, of an 18 carat yellow gold (type 750$Y-3)$, in the cold-rolled condition, are degraded by the effect of heat-treatments at two temperatures. All of the cold-worked strength is removed by heating for more than a few seconds to typical brazing temperatures. The necessity to use high temperatures also increases the process complexity and results in staining

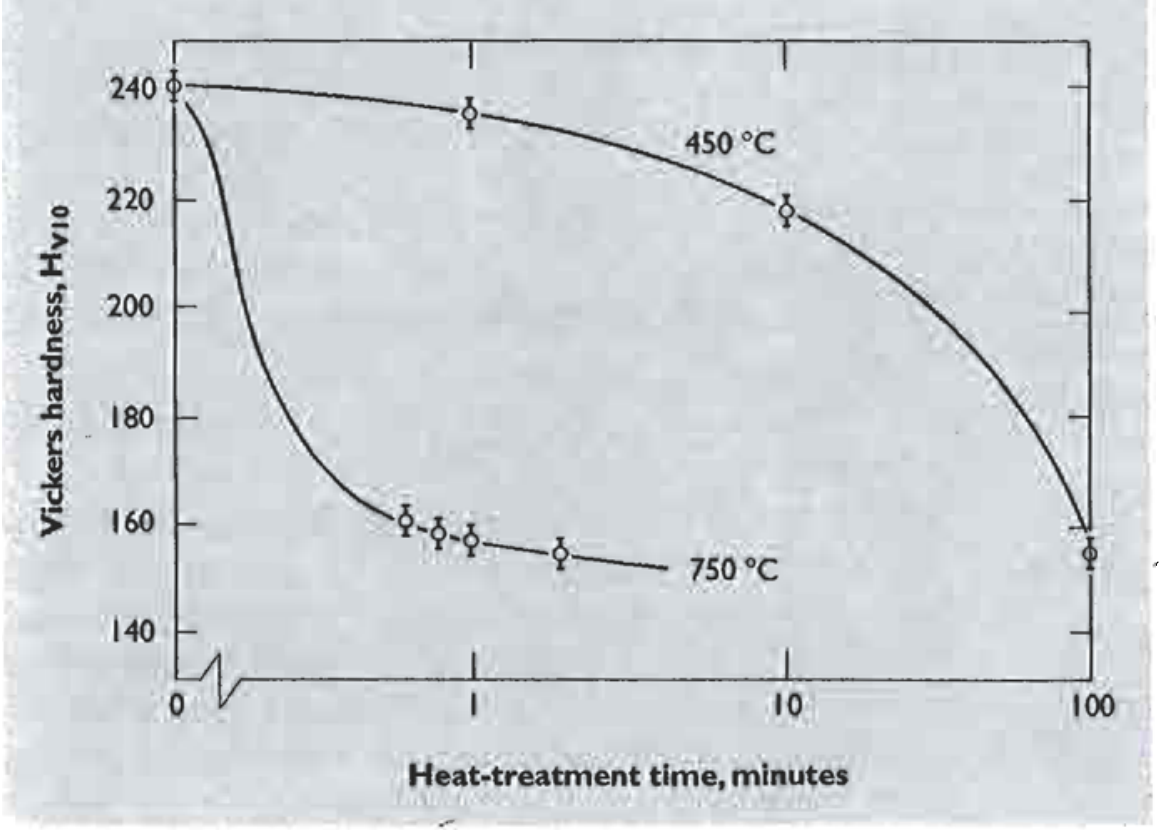

Figure 1

Annealing charateristics of 18 carat yellow gold, in the cold-rolled condition on heat-treatment at 450 and $750^{\circ} \mathrm{C}$ and discolouration of the jewellery through oxidation. The blemishing then has to be removed in special finishing operations.

Clearly, there is a widespread need by the jewellery industry for new, low temperature, joining processes for 18 and higher carat golds and this consideration was the driving force behind the development described in this article.

\section{JoINING PROCESS SELECTION}

The requirements of a joining process for carat gold jewellery are that it must:

- utilise a filler with a gold concentration that satisfies the appropriate hall-marking classification: 75 wt. \% for 18 carat gold, 92 wt. $\%$ for 22 carat gold and $99 \mathrm{wt} . \%$ for 990 gold,

- be colour matched to the jewellery alloy, at least in the standard yellow hues, for aesthetic considerations,

- be useable at sufficiently low temperatures so that the joining may take place without producing significant degradation of the jewellery,

- have good joint filling characteristics, again for aestheric reasons and also in order to maximise the strength of joints,

- have adequate mechanical properties, especially shear strength and resistance to peel failure, these being the primary modes of stressing experienced by jewellery items. A review of the established gold joining technologies used in both the jewellery and engineering industries quickly showed that the processes currently available are not capable of meeting all of these objectives simultaneously and a new approach had to be tried, as explained below. 


\section{EXISTING GOLD JOINING PROCESSES AND THEIR LIMITATIONS}

\section{Carat Gold Solders}

As discussed above, the high working temperature of the carat gold solders degrades the robustness of jewellery.

\section{Engineering Gold Solders}

Gold is unusual in that it is the only metal on which both brazes and solders are based, i.e. this element is a major constituent of both types of filler [2]. The gold solders used in engineering applications are based on the following binary eutectic compositions:

$\begin{array}{llcl}\text { Au-Si } & \text { eutectic point } & \mathrm{Au}-3 \mathrm{wt} . \% \mathrm{Si} & 363^{\circ} \mathrm{C} \\ \mathrm{Au}-\mathrm{Ge} & \text { eutectic point } & \mathrm{Au}-12 \mathrm{wt} . \% \mathrm{Ge} & 361^{\circ} \mathrm{C} \\ \mathrm{Au}-\mathrm{Sb} & \text { eutectic point } & \mathrm{Au}-26 \mathrm{wt} . \% \mathrm{Sb} & 356^{\circ} \mathrm{C} \\ \mathrm{Au}-\mathrm{Sn} & \text { eutectic point } & \mathrm{Au}-20 \mathrm{wt} . \% \mathrm{Sn} & 278^{\circ} \mathrm{C}\end{array}$

The gold-bearing solders are all gold-rich compositions which fortuitously meet the minimum hall-marking specification for 18 carat gold, as they contain at least 75 wt.\% gold and gold-silicon solders potentially could also be used with 22 carat jewellery. Furthermore, they are intrinsically compatible with joining to gold jewellery due to the relatively high slope of the liquidus phase boundary between the various eutectic points and pure gold. In theory this characteristic should help ensure minimal substrate erosion by the molten solder and result in good penetration into long narrow joints.

However, of the gold-bearing solders only the gold-silicon and gold-germanium alloys possess a golden hue. The others are all silvery or metallic grey in colour. Only the gold-rich composition Au- 2 wt.\% Si is available commercially as solder preforms because alloys which contain higher levels of silicon are too brittle to permit their reduction to foil and wire by mechanical working. An additional problem is that molten gold-silicon alloys have high viscosity and do not flow readily, even when aggressive fluxes are used and this property makes them unsuitable for jewellery applications.

\section{Diffusion Bonding}

Gold-to-gold diffusion bonding has the advantage of offering 'seamless' high caratage joints at process temperatures as low as $100^{\circ} \mathrm{C}$. It is also an entirely fluxless process [3]. However, gold diffusion bonding requires subjecting the components being joined to high compressive stresses, typically 10 to $100 \mathrm{MPa}$, for extended periods, usually several hours or more. This type of process is highly unsuitable for most articles of jewellery. 
They would be unable to withstand these conditions without mechanical distortion. Furthermore, to make a diffusion bond it is necessary to ensure that the joint surfaces are scrupulously clean and exceptionally close fitting which would greatly add to manufacturing costs.

\section{AN ALTERNATIVE APPROACH: DIFFUSION SOLDERING}

An alternative low temperature joining method is diffusion soldering. As the name suggests, this is an isothermal joining method which combines features of conventional soldering and diffusion bonding processes and is often fluxless. It is possible to design processes of this type that combine the good joint filling and degree of tolerance to surface preparation which characterises conventional soldering and brazing, together with the flexibility with regard to joint homogeneity that is available from diffusion bonding.

Making a diffusion soldered joint involves placing a thin layer of solder between the components to be joined and heating the assembly to a temperature above the melting point of the solder. By judicious choice of the combination of solder and substrate, their relative thicknesses and the processing conditions, the solder can be made to react with the substrates to form phases which are solid at the joining temperature, within realistic time-scales. The sequence of steps involved in making a diffusion soldered joint is illustrated schematically in Figure 2. Other advantages of this type of joining process are:

- The necessary applied pressures are much lower than those required for diffusion bonding, merely enough to force the faying surfaces together, and are typically 0.2 to $2 \mathrm{MPa}$ for jewellery applications.

- Exceptionally good joint filling can be achieved, even over large areas.

- The joints are very thin, usually less than $5 \mu \mathrm{m}$, which benefits the mechanical properties and is important when the filler alloy is a solder.

- Crisp joint edges can be achieved, with controlled sizes of fillets which can vary from essentially non-existent to similar to those of a conventional brazed joint.
The first two of these features derive from the generation of liquid in the joint during the joining process while the second pair are a consequence of the volume of filler metal being smaller and more precisely controlled than in conventional filler metal joining.

Several diffusion brazing and diffusion soldering processes have been developed, a review of which is given by Jacobson and Humpston [4]. Likewise, the underlying physical metallurgy of such processes has been extensively studied by experiment and mathematical modelling $[5,6]$.

A study was undertaken to assess the feasibility of diffusion soldering to gold. If the results proved encouraging, it was then planned to develop the process for 18 carat gold, which is the largest single market for gold jewellety, followed by 22 carat alloys and the new 990 gold [7].

\section{CANDIDATE DIFFUSION SOLDERING SYSTEMS}

Five low melting point metals form the basis of common solder alloys, namely:

$\begin{array}{llr}\text { - Gallium } & \text { melting point } & 30^{\circ} \mathrm{C} \\ \text { - Indium } & \text { melting point } & 157^{\circ} \mathrm{C} \\ \text { - Tin } & \text { melting point } & 232^{\circ} \mathrm{C} \\ \text { - Bismuth } & \text { melting point } & 271^{\circ} \mathrm{C} \\ \text { - Lead } & \text { melting point } & 328^{\circ} \mathrm{C}\end{array}$

These metals were considered in turn for making diffusion soldered joints to gold.

In expetimental investigations it was found that gallium and indium were unsuitable, in these cases owing to the formation of brittle intermetallic phases with gold and weak interfaces between such phases. Bismuth was excluded from consideration because it is a hard, brittle metal and cannot be readily deposited onto substrates by wet plating methods. Only wet plating was considered viable as a technique for applying layers of solder metals several microns thick onto jewellery components.

Lead was dismissed on account of the environmental and health hazards associared with its use. This left tin as the only obvious candidate metal. 
The gold-tin phase diagram, which is reproduced in Figure 3, shows that molten tin reacts with gold to form several intermetallic compounds. It is well established that the tin-rich compounds are hard and britthe and form weak interfaces with other phases [8]. Whenever tin-based solders are used for joining gold- difficult to remove from a joint by diffusion within realistic time-scales. Accordingly, a low temperature diffusion soldering process based on this system has to be ruled out. However, consideration of the gold-tin phase diagram shows that provided the joining temperature exceeds $419^{\circ} \mathrm{C}$, the tin-rich phases will melt, so

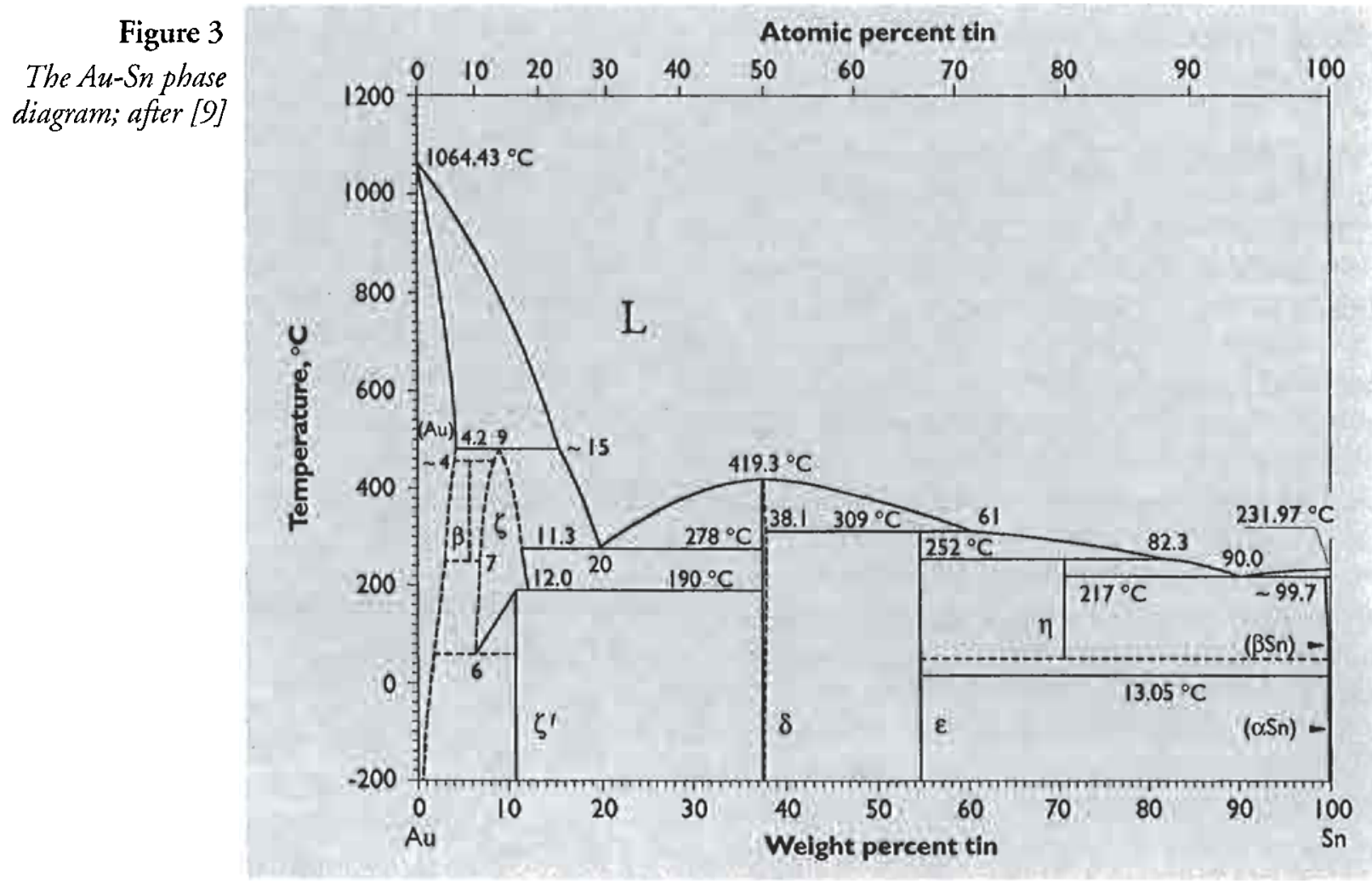

coated components, precautions should be taken to restrict the formation of these phases because they can have a catastrophic effect on the mechanical properties of joints [10].

Measurements were made in order to establish the kinetics of reaction between molten tin and gold using apparatus and an experimental procedure similar to that described by Evans and Denner [11]. The results, which are presented in Figure 4, clearly demonstrate the very high rate of reaction between tin and gold and also its temperature dependence, as has been reported elsewhere [12]. This behaviour is consistent with the shallow slope of the liquidus boundary, that ascends towards the intermetallic compound $\mathrm{AuSn}$, on the tin-rich side of the gold-tin phase diagram.

The tin-rich gold-tin intermetallic compounds are relatively stable and, once formed, would be that the product of reaction will then be the formation of the gold-rich intermetallic compound based on $\mathrm{Au}_{5} \mathrm{Sn}$. Not only does this phase contain approximately $90 \mathrm{wt} . \%$ gold and therefore amply meet the caratage requirements for 18 carat jewellery but, because the phase exists over a range of composition, it is likely to possess reasonable mechanical properties [13].

The first series of bonding trials was carried out using copper coupons electroplated with a layer of gold $10 \mu \mathrm{m}$ thick. These test pieces had the advantage of being sufficiently cheap to enable the new process to be developed in a systematic series of experiments. Over the gold plating, a layer of tin was applied, also by electroplating, in a range of thicknesses. To make a diffusion soldered joint, pairs of coated substrates were placed in contact, inserted into a nitrogen atmosphere furnace and a compressive stress of $5 \mathrm{MPa}$ 
applied. The temperature of the furnace was then raised to $450^{\circ} \mathrm{C}$ and maintained for 15 minutes before cooling back to room temperature.

The resulting joints were well filled, strong and reasonably ductile, but lighter in colour than the pure gold electroplate. By extending the dwell time at the bonding temperature it was found to be possible to promote sufficient diffusion to eliminate the colour difference.

During the period in which this work was being carried out, a paper appeared in the technical literature which lent encouragement to the diffusion soldering process being investigated. In this article, a research group at the University of California, Irvine, described a bonding process in which layers of gold, tin, and again gold of prescribed thickness are evaporated onto semiconductor dies [14]. By raising the temperature to $260^{\circ} \mathrm{C}$, the tin melts and reacts with the gold to form the gold-rich gold-tin eutectic. This is essentially the same diffusion soldering process, albeit in a different configuration, and was proposed by the American authors as a lower temperature alternative to the pre-placement of Au- 20 wt.\% Sn eutectic foil preforms which are widely used in the electronics industry. Here, the layer of tin is a mere $2 \mu \mathrm{m}$ thick, which is only possible because the component surfaces have mirror finishes. Another difference with the process for gold jewellery is that the end phases of the reaction are $\mathrm{Au}_{5} \mathrm{Sn}$ and $\mathrm{AuSn}$ which bound the eutectic reaction, rather than gold solid solution. A further publication by the same group furnishes comprehensive thermodynamic and kinetic reaction data for the gold-rich portion of the gold-tin system [15].

The encouraging results of the bonding trials described above and the supporting information emerging in the literature prompted a study to establish whether the diffusion soldering process would operate successfully with 18 carat and other jewellery alloys and to determine suitable process conditions and their tolerance to variation. The mechanical integrity of the joints formed was also examined and compared with that obtainable in conventional soldered and diffusion bonded joints.

\section{DIFFUSION SOLDERING 18 CARAT GOLD USING TIN}

In order to further develop the diffusion soldering process using tin as the solder, for application to 18 carat jewellery, the aspects that needed to be addressed were as follows:

- Caratage limits of jewellery alloys for this process

- Temperature limits on the process.

- Thickness of the tin layer as a process parameter.

- Effect of heating/cooling rates and heating duration on joint quality.

- Minimum applied pressure for bonding to take place.

- Colour matching of the joints.

- Mechanical properties of joints made under optimised process conditions.

The work undertaken to characterise these variables is described below. Based on these trials, which were successful, process specifications for the production of diffusion soldered joints to 18 and 22 carat gold and also 990 gold were formulated and are given in the appendix on page 103.

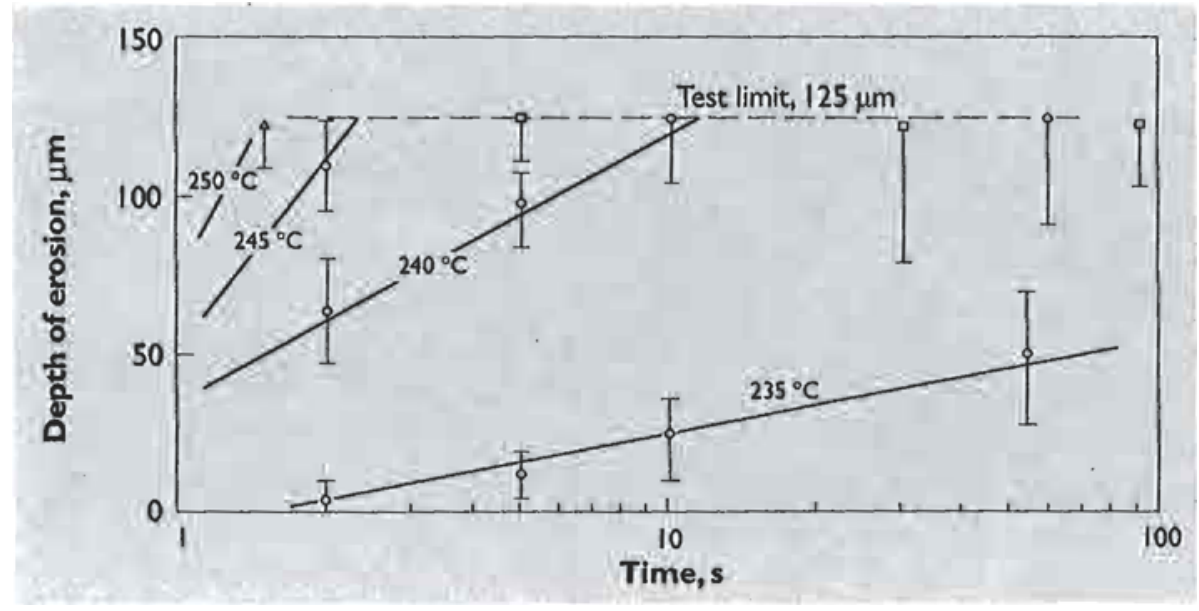

Figure 4

Erosion of gold by molten tin as a function of reaction time and temperature 


\section{ESTABLISHMENT OF A VIABLE PROCESS}

The following aspects were evaluated in relation to the bonding process:

\section{CARATAGE OF THE GOLD SUBSTRATES}

As noted in the previous section, the initial stage in the evaluation of the gold-tin diffusion soldering process was carried out using test pieces having surfaces of pure gold. The majority of gold jewellery is 18 carat yellow gold, designation $750 \mathrm{Y}-3$, i.e. of composition $75 \mathrm{Au}$ $12.5 \mathrm{Ag}-12.5 \mathrm{Cu}$ (wt.\%) [16]. Accordingly, full characterisation and optimisation of the process was car-

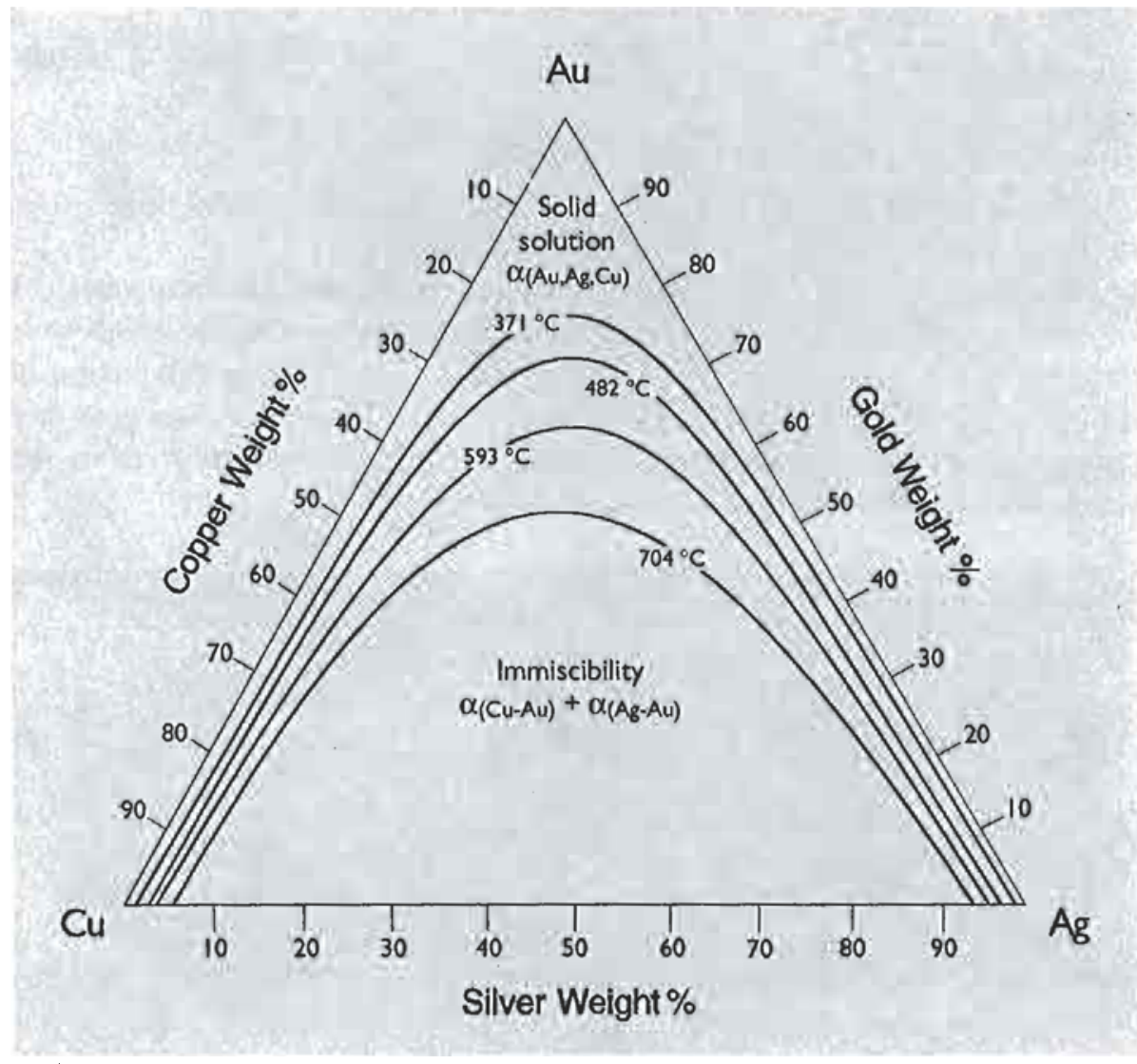

Figure 5

Solidus projection of the $\mathrm{Ag}-\mathrm{Au}$-Cu phase diagram.

The figure shows projections on the room temperature plane of the ternary phase diagram of the solid state boundary of the immiscibility field at several temperatures; after [17] ried out using sheets of this alloy as substrate. (It has subsequently been shown to be also applicable to all 18 carat yellow golds, including the zinc-containing formulations.)

No changes to the parameters of the diffusion soldering process were required as a result of the switch to 18 carat yellow gold substrates in place of pure gold. This is to be expected from consideration of the goldsilver-copper phase diagram, the solidus projection of which is given in Figure 5. It can be seen from the phase diagram that copper and silver form a solid solution with gold provided that the gold concentration is higher than $70 \mathrm{wt} . \%$, at $450^{\circ} \mathrm{C}$. This temperature is the optimum for carrying out diffusion soldering using the gold-tin system, as determined in this study (see below). In other words, the constitutional data confirmed that the presence of copper and silver in the alloy does not significantly affect the metallurgical characteristics of the joints provided that the substrates are more noble than 17 carat. Therefore the tin-based diffusion soldering process developed is also metallurgically suitable for 22 carat and 990 gold jewellery.

At the diffusion soldering temperature of $450^{\circ} \mathrm{C}$ the gold-silver-copper phase diagram shows that jewellery alloys of lower caratage have a duplex microstructure, consisting of silver-gold and copper-gold solid solutions. Copper-gold solid solutions are not compatible with tin filler alloys because extensive Kirkendall voids form during the alloying process, which would greatly weaken the joints. Only by applying extremely high compressive stresses to the assembly during the heating cycle can this phenomenon be suppressed [18], which would be undesirable for jewellery applications. 


\section{PROCESS TEMPERATURE LIMITS}

The minimum permissible process temperature can be deduced from the phase relationships between gold and tin, because the silver and copper constituents of the jewellery alloy are in solid solution in the gold above about $375^{\circ} \mathrm{C}$. It can be seen from the gold-tin phase diagram, which is given in Figure 3, that in order to prevent the formation of the tin-rich intermetallic compounds the assembly must be heated above $419^{\circ} \mathrm{C}$. Then, the tin will react with the gold to form, initially, $\mathrm{Au}_{5} \mathrm{Sn}$. As this phase contains approximately $90 \mathrm{wt} . \%$ gold it meets the caratage requirements of a joint in 18 carat jewellery. It is desirable in any implementation of the diffusion soldering process to use a temperature slightly above the minimum value in order to ensure that all of the joint region exceeds $419^{\circ} \mathrm{C}$, allowing for errors in temperature calibration and the presence of thermal gradients in the assembly.

The maximum process temperature is fixed by the need to limit softening of the gold jewellery due to annealing and grain growth. From the data of annealing characteristics of cold-worked 18 carat gold given in Figure 1 it can be seen that for a ten minute heating cycle, the recrystallisation onset temperature, above which the alloy rapidly softens, is approximately $450^{\circ} \mathrm{C}$. It is therefore desirable that the maximum temperature for the gold- tin diffusion soldering process does not exceed $450^{\circ} \mathrm{C}$. Because, as will be shown below, the diffusion soldering takes about one hour to complete, some annealing of the substrates will have occurred during the heating cycle. However, the extent of the softening is small by comparison with that caused by joining of 18 carat gold jewellery items at $750^{\circ} \mathrm{C}$, using a conventional carat gold solder.

Although similar reasoning means that the same maximum recommended process temperature applies also to 22 carat gold, the same is not true for 990 gold. The metallurgy of 990 gold differs from that of conventional carat jewellery alloys and the mechanical properties are actually improved by heat-treatment for one hour at $500{ }^{\circ} \mathrm{C}$, provided that the alloy has been previously solution-treated [7]. Thus, diffusion soldering using tin offers the prospect of carrying out the precipitation heat-treatment of 990 gold jewellery simultaneously with joining it. For economic reasons, the recommended process temperature for diffusion soldering of 990 gold is therefore $500{ }^{\circ} \mathrm{C}$.

\section{THICKNESS OF THE TIN ELECTROPLATE}

A diffusion soldering process functions by converting all of the low melting point phases to more stable phases by diffusion through heating. 'Thus, the optimum thickness of the solder layer is that which generates sufficient liquid to completely fill the joint gap but yet can be removed rapidly at the process temperature by diffusion. To a limited extent, the minimum volume of solder required is also dictated by the rate of heating to the process temperature because some diffusion of tin into gold will take place while the solder is being heated to its melting point. The mininum heating rate used in the trials was $10^{\circ} \mathrm{C} /$ min which, being a relatively low rate, can be taken as representative of a worst-case condition for an industrial process.

A series of 18 carat test pieces was prepared, the test pieces being coated with a layer of tin between 1 and $20 \mu \mathrm{m}$ thick and bonded to matching substrates using identical process conditions. As a result of this trial, it was established that the minimum thickness of the tin layer is strongly dependent on the joint gap. But, given that a compressive stress is applied to minimise the joint gap, a 3 to $4 \mu \mathrm{m}$ thick layer of tin is generally sufficient to ensure complete joint filling and the production of small edge fillets.

\section{DURATION OF THE PROCESS CYCLE}

The duration of a diffusion soldering process cycle is substantially longer than that needed in a conventional soldering process. This is because of the need to homogenise the joint by diffusion. The time needed to achieve homogenisation of a gold-tin diffusion soldered joint is dependent on the rate of diffusion of tin into gold, which is controlled by the temperature and time of the heat-treatment and the volume of tin i.e. the thickness of the tin layer. Unduly long homogenisation heat-treatments are clearly undesirable in a commercial manufacturing context, because they impose cost penalties and reduce throughput. They also lead to a marked softening of the jewellery items, which then necessitates a further cycle of heat-treatment to restore the hardness. A criterion which limits the minimum length of the heat-treatment period is that sufficient diffusion of tin out of the joint must take 
place so that the hue of the joints is indistinguishable from that of the jewellery items, for aesthetic reasons.

The colour matching of the joints was observed visually by comparing metallographic sections against reference standards of 18 carat gold sheet. The test pieces and the reference standards were prepared by polishing with $0.3 \mu \mathrm{m}$ diameter alumina powder embedded in a soft cloth. This procedure removed extraneous surface films and helped to ensure, as far as possible, that interpretation of the observed features was not clouded by spurious detail.

With the diffusion soldering process temperature fixed at $450^{\circ} \mathrm{C}$ and the tin thickness at $4 \mu \mathrm{m}$, systematic trials were carried out to follow the colour change as a function of the heating cycle duration as the tin diffused into the gold. It was observed that the joints did not differ significantly in hue from the substrates provided that the dwell time at $450{ }^{\circ} \mathrm{C}$ was of the order of one hour.

\section{COMPRESSIVE STRESS APPLIED DURING THE BONDING CYCLE}

In order to ensure complete joint filling with the small volume of solder available in a diffusion soldering process it is necessary for the faying surfaces to be pressed together while the solder is molten. In applications such as ring sizing, the natural springiness of the jewellery will produce the desired effect. For other styles of joint, the compressive stress applied to the joint must be sufficient to elastically deform the components and force the abutting components into intimate contact.

No data for the elastic modulus of 18 carat gold in the cold worked condition could be found in the published literature. The data necessary for calculating this parameter were obtained by conducting a tensile test on a $200 \mu \mathrm{m}$ thick sheet using a strain rate of $10 \mathrm{~mm} / \mathrm{min}$. The calculated Young's modulus is $60 \mathrm{GPa}$. Accordingly, a compressive stress of $1 \mathrm{MPa}$ (equal to a $100 \mathrm{~g}$ load acting on a $1 \mathrm{~mm}^{2}$ area) is more than adequate for achieving well-filled joints in 18 carat gold sheet, in the cold-worked condition.

\section{EVALUATION OF THE JOINTS}

Joints were made using the optimised process conditions and then subjected to a range of homogenisation heat-treatments. They were assessed and qualified as described below.

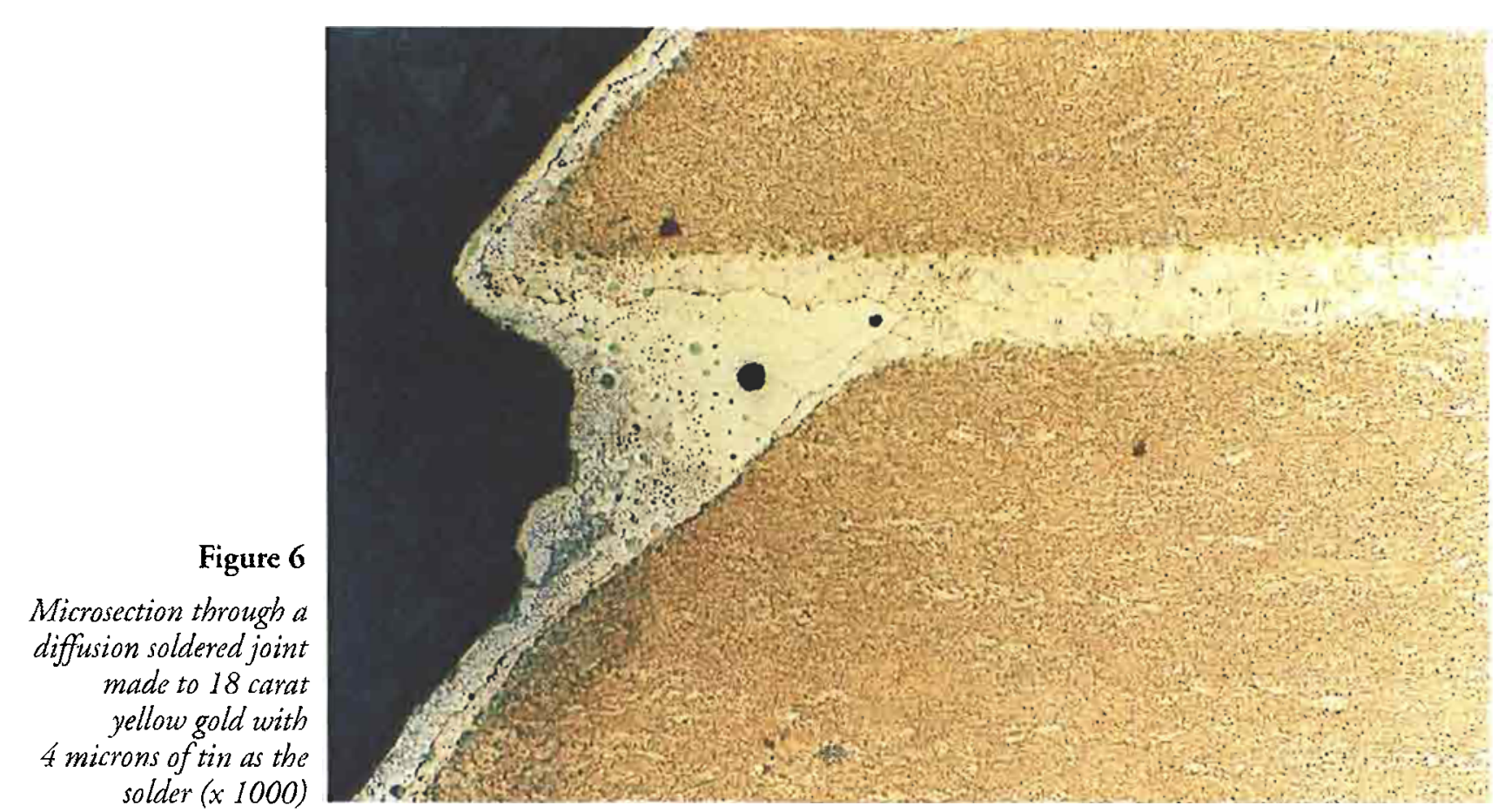




\section{METALLOGRAPHIC EXAMINATION}

Joints were metallographically examined after bonding. After polishing, the microstructure of the joints was revealed by etching them in a dilute solution of potassium iodide in potassium cyanide.

Micrographs of longitudinal sections through joints made with $4 \mu \mathrm{m}$ of tin are shown in Figures 6, 7 and 8. As bonded (Fig. 6), the substrate alloy shows a fine wrought grain structure and the joint is evident as a central band of lighter hue. No other phases can be discerned in the joint region, from which it is concluded that the tin has diffused into the gold alloy substrates to form the gold-rich phase $\mathrm{Au}_{5} \mathrm{Sn}$. A small fillet has formed at the edge of the joint. To the naked eye, the joints appeared to be lighter in hue than the gold substrates so that further heat-treatment to reduce the local concentration of tin is necessary.

Following the recommended homogenisation heat-treatment of one hour at $450{ }^{\circ} \mathrm{C}$, the joints are largely homogeneous with the substrates, as can be seen in Figure 7. The colour matching with the substrates is then excellent. A joint given an extended heat-treatment of 60 hours at $450^{\circ} \mathrm{C}$ is shown in Figure 8. In addition to very significant grain growth in the jewellery alloy there is some evidence of voids in the joint centre line. Because the tin was applied to only one of the component surfaces, it would appear that these voids are being formed by a Kirkendall mechanism, presumably associated with the presence of copper in the jewellery alloy. Therefore, there is a good reason for restricting the homogenisation heat-treatment time to about one hour. Furthermore, as discussed above, there is no benefit, from the point of view of colour matching, in continuing the heat-treatment for longer periods.

\section{MECHANICAL PROPERTIES OF JOINTS}

The strength of joints made using the optimised process conditions was assessed in shear and peel because it was considered that these modes of stressing are most relevant to articles of jewellery.

The shear strength of joints was assessed by preparing single lap joints and applying tensile loading, in a universal testing machine at a cross-head speed of $10 \mathrm{~mm} / \mathrm{min}$, until failure occurred.

Different test piece configurations were used as specified in Table 1 .

Altogether, nine single lap joints were prepared in order to measure the shear strength. The results are

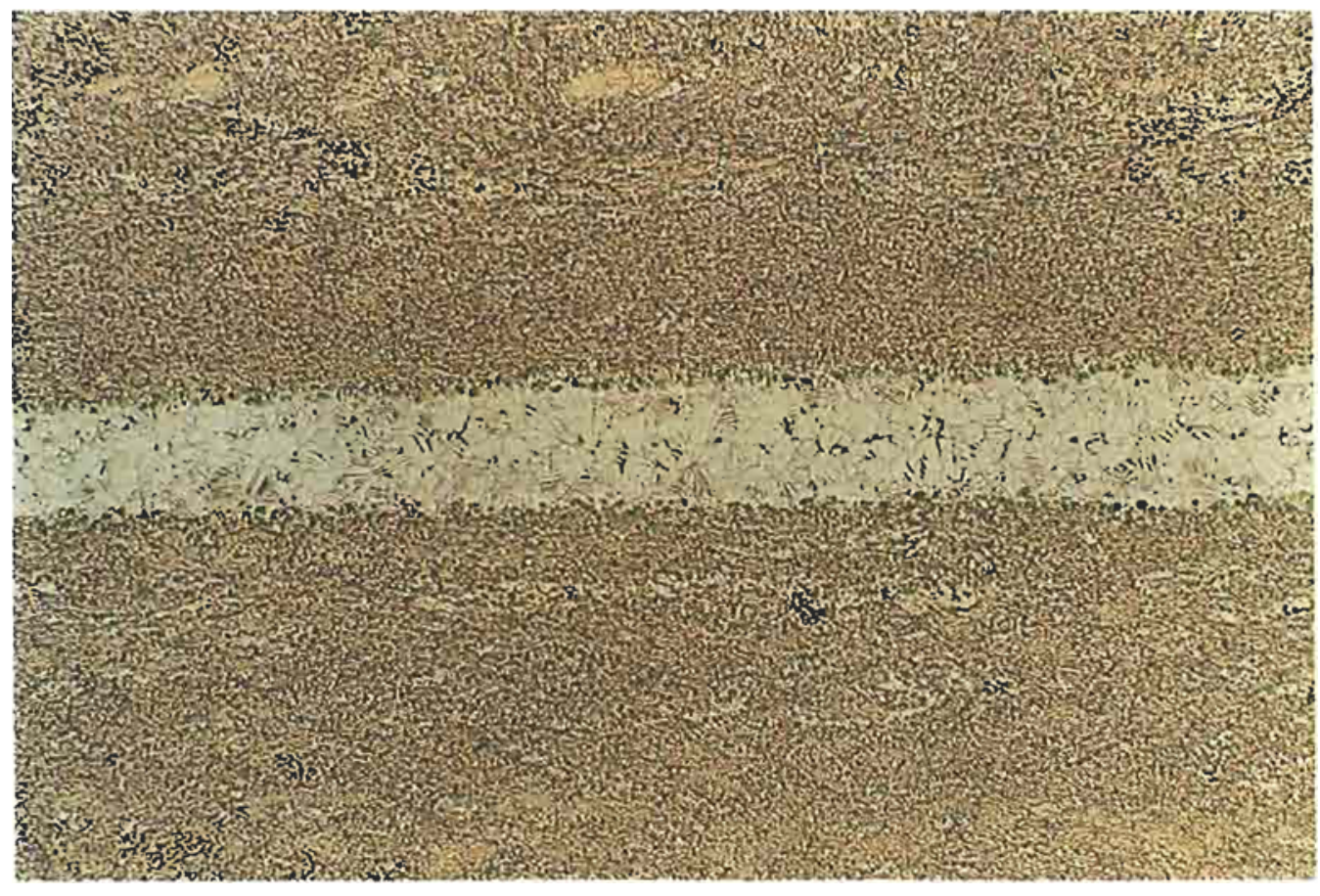

Figure 7

Microsection through a diffusion soldered joint made to 18 carat yellow gold with 4 microns of tin as the solder, following beat-treatment at $450^{\circ} \mathrm{C}$ for one hour $(x$ 1000) 


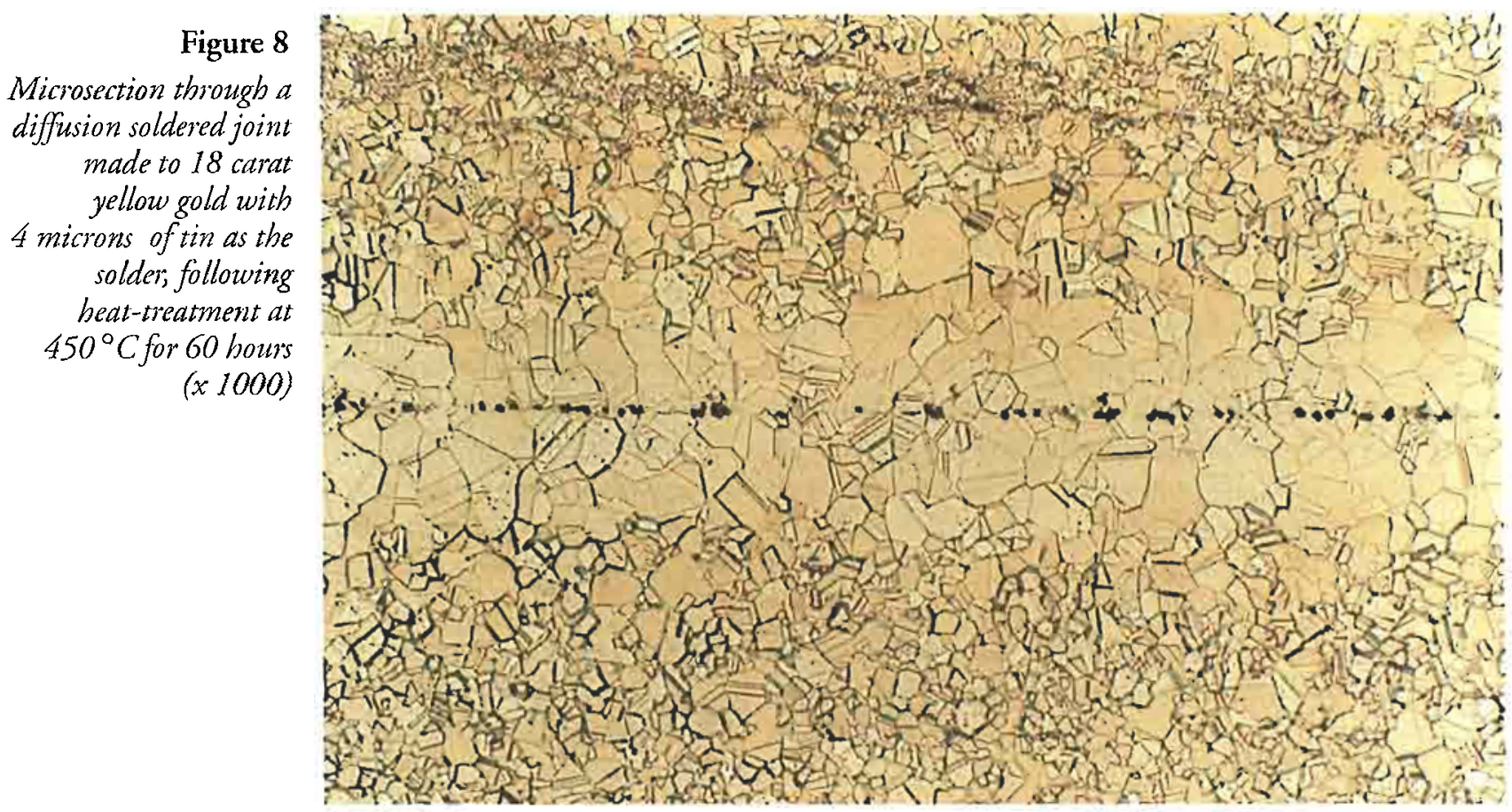

given in Table 1. The test pieces failed either in the machine grips or the substrate, but always outside of the joint. The substrate failure stress in tension is in close agreement with published values for the ultimate tensile stress (UTS) of 18 carat gold [16]. This means that the joints are capable of supporting a shear stress of at least $60 \mathrm{MPa}$, which approaches the stress at which joints made to copper components using the industry standard, eutectic lead-tin solder, fail in shear [19]: they may well be substantially stronger. To subject diffusion soldered joints to shear stresses that are closer to the failure stress of the parent material requires much larger 18 carat gold test pieces than those used in the current study and these could not be justified on grounds of cost.

\begin{tabular}{|c|c|c|c|c|c|c|}
\hline & $\begin{array}{l}\text { Sample } \\
\text { number }\end{array}$ & $\begin{array}{c}\text { Joint } \\
\text { length }(\mathrm{mm}) \\
\text { x width }(\mathrm{mm}) \\
\text { x substrate } \\
\text { thickness, }(\mu \mathrm{m})\end{array}$ & $\begin{array}{l}\text { Failure } \\
\text { load, N }\end{array}$ & $\begin{array}{c}\text { Failure } \\
\text { position }\end{array}$ & $\begin{array}{c}\text { Substrate } \\
\text { tensile } \\
\text { strength, } \\
\text { MPa }\end{array}$ & $\begin{array}{c}\text { Shear } \\
\text { stress } \\
\text { supported } \\
\text { by joint, } \\
\mathrm{MPa}\end{array}$ \\
\hline \multirow{6}{*}{ Table 1} & I & $11.89 \times 10.80 \times 200$ & 1.460 & in grips & 676 & $>11.4$ \\
\hline & 2 & $9.65 \times 10.4 \times 200$ & 930 & $"$ & 445 & $>9.2$ \\
\hline & 3 & $5.08 \times 19.65 \times 200$ & 1.562 & $"$ & 391 & $>13.5$ \\
\hline & 4 & $9.54 \times 11.30 \times 200$ & 1,182 & in substrate & 523 & $>11.0$ \\
\hline & 5 & $9.82 \times 12.30 \times 200$ & 1,183 & $"$ & 481 & $>9.8$ \\
\hline & 6 & $7.06 \times 17.40 \times 200$ & 1,200 & $"$ & 354 & $>9.7$ \\
\hline $\begin{array}{l}\text { Shear strength of } \\
\text { diffusion soldered joints }\end{array}$ & 7 & $3.42 \times 4.12 \times 500$ & 723 & $"$ & 350 & $>51.3$ \\
\hline made to 18 carat & 8 & $3.99 \times 4.30 \times 500$ & 1,154 & in grips & 536 & $>67.2$ \\
\hline $\begin{array}{r}\text { yellow gold using } \\
4 \text { microns of tin as the } \\
\text { solder }\end{array}$ & 9 & $4.13 \times 4.14 \times 500$ & 1,064 & " & 513 & $>62.2$ \\
\hline
\end{tabular}


For the peel tests, 'T-shaped test pieces were prepared using $200 \mu \mathrm{m}$ thick sheet with joint dimensions of close to $10 \times 10 \mathrm{~mm}$. These were then torn apart in a controlled manner using a universal testing machine at a cross-head speed of $10 \mathrm{~mm} / \mathrm{min}$. The tests were subsequently repeated but using a slower straining rate of $1 \mathrm{~mm} / \mathrm{min}$ and with the joint width decreased to approximately $3 \mathrm{~mm}$. The measured peel strengths of nine joints are given in Table 2. The load per unit joint width required to initiate peel is approximately $20 \mathrm{Nm}^{-1}$, and is frequently much higher. This value is more than double that measured for lead-tin eutectic joints to copper $\left(9 \mathrm{Nm}^{-1}\right)[19,20]$, but close to that of diffusion bonded joints to aluminium $\left(21 \mathrm{Nm}^{-1}\right)$ used in the aviation industry [21]. It is therefore reasonable to assume that the strength and resistance to peel of diffusion soldered joints made with tin is likely to be adequate for jewellery applications.

\section{PRACTICAL APPLICATION OF THE PROCESS}

Initial trials to apply the new joining process to jewellery fabrication have been carried out, involving an 18 carat gold bracelet and matching ear-ring set [22].
Figure 9 shows the earrings and a part of the bracelet, with components of one link of the bracelet in order to indicate the construction. After assembly the joints are practically invisible. Crisp joint edges were achieved and the finishing operations required were simpler than those needed for brazed jewellery. The jewellery design was commissioned by the World Gold Council from County Classics (of Hatton Garden, London) and first shown publicly on the 'New Technology' stand of the World Gold Council at the World Jewellery Trade Fair held in Basel 1992.

The trials provided a convincing demonstration that the diffusion soldering process is practicable and suitable for application to complex designs and shapes in 18 carat gold. The encouraging results obtained provide an incentive for progressing towards further refinement and commercial exploitation of the process. Accordingly, two further aspects were addressed, namely improving the ease of introducing the solder into the joint and developing a flux so that joints could be made in air using either a torch or a simple furnace.

\section{SOLDER PREFORMS}

Selectively electroplating the regions of jewellery items to be joined with a thin and highly uniform layer of tin requires investment of capital in the electroplating

\begin{tabular}{|c|c|c|c|c|}
\hline $\begin{array}{l}\text { Sample } \\
\text { number }\end{array}$ & $\begin{array}{l}\text { Joint width }(\mathrm{mm}) \\
\times \text { joint length }(\mathrm{mm})\end{array}$ & $\begin{array}{l}\text { Failure } \\
\text { load, N }\end{array}$ & $\begin{array}{l}\text { Failure } \\
\text { position }\end{array}$ & $\begin{array}{c}\text { Peel } \\
\text { strength, } \\
\text { N per mm } \\
\text { joint width, } \\
\left(\mathrm{Nmm}^{-1}\right)\end{array}$ \\
\hline 1 & $10.81 \times 20.0$ & 152 & in joint & 14.1 \\
\hline 2 & $10.50 \times 20.0$ & 176 & $"$ & 16.8 \\
\hline 3 & $10.05 \times 20.0$ & 277 & $"$ & 27.6 \\
\hline 4 & $3.40 \times 20.0$ & 155 & in substrate & $>45.6$ \\
\hline 5 & $3.37 \times 20.0$ & 132 & " & $>39.2$ \\
\hline 6 & $3.47 \times 20.0$ & 133 & $"$ & $>38.3$ \\
\hline 7 & $3.37 \times 20.0$ & 59 & in joint & 17.5 \\
\hline 8 & $3.65 \times 20.0$ & 115 & in substrate & $>31.5$ \\
\hline 9 & $3.97 \times 20.0$ & 106 & 17 & $>26.7$ \\
\hline
\end{tabular}

\section{Table 2}

Peel sresistance of diffusion soldered joints made to 18 carat yellow gold using 4 microns of tin as the solder 
plant and not inconsiderable expertise to carry out. A more practical method of introducing the solder into the joint region is as a foil preform which could be made commercially available by suppliers. Because a tin foil a few microns thick is too fragile to be handled, the tin is electrodeposited on to an annealed gold foil about $75 \mu \mathrm{m}$ thick which acts as a carrier. The carrier is coated with tin on both sides so that two joints are made simultaneously in the diffusion soldering cycle.

By making the carrier foil from an alloy that is slightly more gold-rich than the caratage of the jewellery alloy it is possible to compensate for the small addition of tin to the jewellery item and thereby guarantee that it will meet the caratage standard absolutely.

\section{FLUXED JOINING IN AIR}

The majority of jewellery fabrication is carried out in air. To make a diffusion soldered joint in air it is necessary to use a flux. The role of this flux is to prevent the oxidation of the tin, while the solder is molten and also to remove tarnishing from the surfaces of the abutting carat gold components. Ideally, the flux should be formulated so

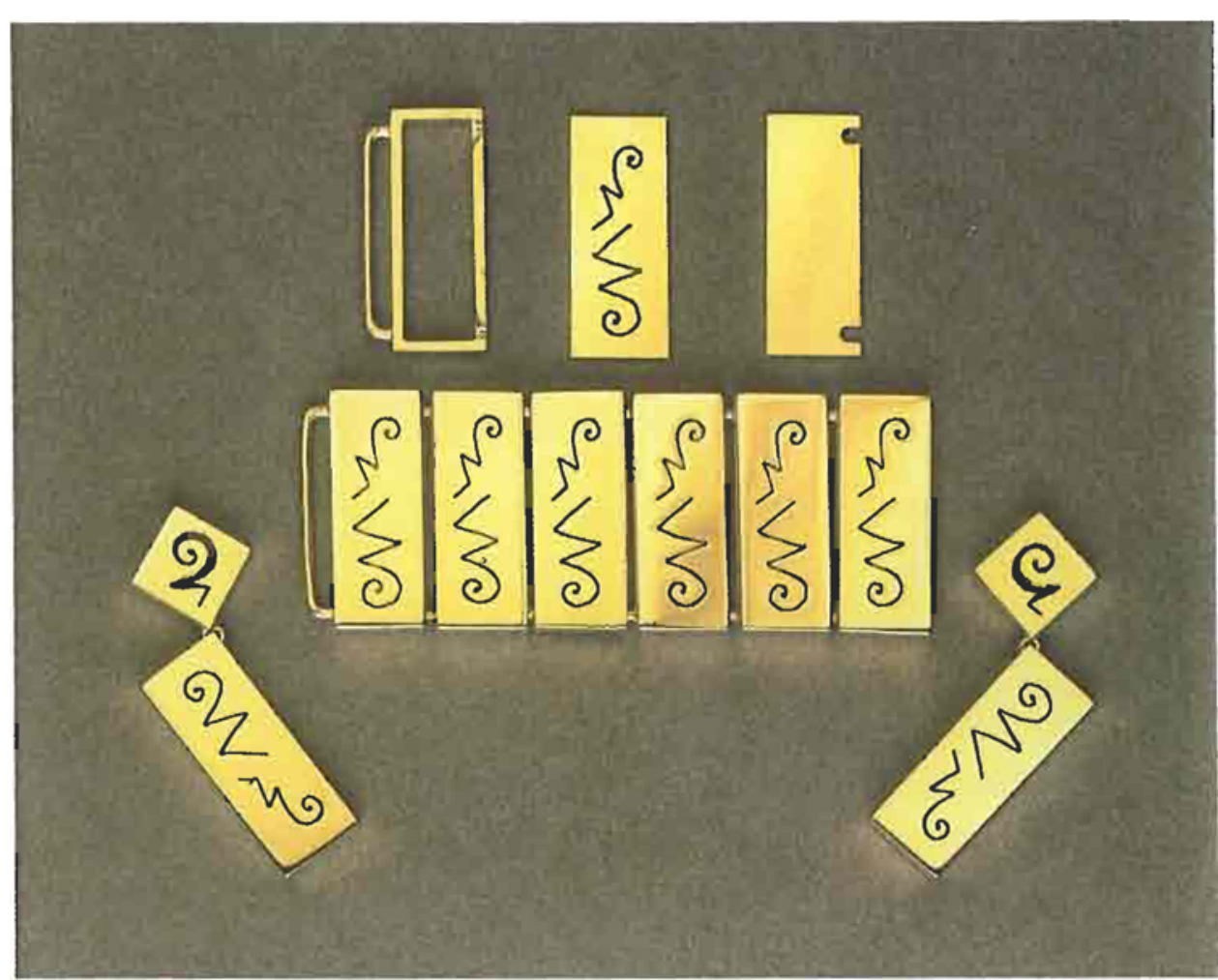

Figure 9

Parts of an 18 carat gold bracelet and matching ear-ring set assembled by the new diffusion soldering process at $450^{\circ} \mathrm{C}(x 1)$

that any excess and the flux residues volatilise on heattreatment at $450{ }^{\circ} \mathrm{C}$. Then special post-joining cleaning procedures are not required. Fluxes that fulfil these requirements are available commercially in a range of forms, e.g. ARAX liquid flux, made by Mulricore Solders Ltd., Hemel Hempstead, UK.

A diffusion soldered joint can be made in air by first dipping the solder foil preform in the liquid flux prior to inserting it into the joint gap. The assembly is then heated to about $250^{\circ} \mathrm{C}$, at which temperature the flux is chemically active and aids wetting of the joint surfaces by the molten tin. In a belt furnace the work. can then pass through to a second hotter zone where the temperature should exceed $420^{\circ} \mathrm{C}$, in order to remove the low melting point tin-rich phases from the joint gap and homogenise the microstructure. Experiments showed that once the solder had melted, flowed, filled the joint and isothermally solidified - which is achieved within a few tens of seconds at $250^{\circ} \mathrm{C}$ - the jewellery could be removed from the bonding jig and the homogenisation heat-treatment completed sub- 


\section{CONCLUSIONS}

Diffusion soldering of 18 carat yellow gold alloys using pure tin as the filler metal has been evaluated and found to be practicable. The influence of process variables on joint quality has been investigated and this has enabled a provisional process specification to be devised, which is presented in the appendix. The process can also be used to join 22 carat and 990 gold jewellery.

The mechanical properties of diffusion soldered joints have been measured in overlap shear and in peel. The strength of the joints was greater than that of the sheets of 18 carat gold used as the test pieces and is therefore likely to be sufficiently robust for jewellery applications.

\section{ACKNOWLEDGEMENTS}

The World Gold Council is gratefully acknowledged for the funding of this work.

\section{APPENDIX}

\section{Process conditions for diffusion soldering 18 carat gold using tin solder}

Caratage of the jewellery alloy:

Preform:

Minimum heating rate from room temperature to the process temperature:

Process temperature:

Process atmosphere:

Compressive stress applied during the bonding cycle:

Minimum time at the process temperature with the compressive stress applied:

Homogenisation heat-treatment temperature:

Homogenisation heat-treatment time:
18 and 22 carat, all yellow hues, plus 990 gold

$75 \mu \mathrm{m}$ thick annealed foil of appropriate caratage, coated on both sides with $3-4 \mu \mathrm{m}$ of bright tin electroplate

$10^{\circ} \mathrm{C} / \mathrm{min}$

$435 \pm 15^{\circ} \mathrm{C} ; 500 \pm 10^{\circ} \mathrm{C}$ recommended for 990 gold, to be compatible with the precipitation heat-treatment either: inert gas (e.g. argon, nitrogen) or vacuum $(<1 \mathrm{mPa})$; oxygen level $<10 \mathrm{ppm}$

or: air using a suitable flux (e.g. ARAX liquid from Multicore Solders, Hemel Hempstead, UK)

Sufficient to force the faying surfaces into intimate contact (typically $1 \mathrm{MPa}=100 \mathrm{~g} / \mathrm{mm}^{2}$ )

30 seconds

$450^{\circ} \mathrm{C}$

1 hour 


\section{REFERENCES}

1. W.S. Rapson \& T. Groenewald, Gold Usage, Academic Press, 1978

2. G. Humpston \& D.M. Jacobson, 'Principles of Soldering and Brazing', ASM International, 1993

3. D.L. Ornellas \& E. Catalano, 'Diffusion Bonding of Gold-to-gold', Review of Scientific Instruments, 1974, 45(7), 955

4. D.M. Jacobson \& G. Humpston, 'Diffusion Soldering', Soldering and Surface Mount Technology, 1992, 10(2), 27-32

5. Isaac Tuah-Poka, M. Dollar \& T.B. Massalski, 'A Study of the Transient Liquid Phase Bonding Process Applied to a $\mathrm{Ag} / \mathrm{Cu} / \mathrm{Ag}$ Sandwich Joint', Metallurgical Transactions A, 1988, 19A,(3), 675686

6. H. Nakagawa, C.H. Lee \& T.H. North, 'Modelling of Base Metal Dissolution Behaviour during Transient Liquid-phase Bonding', Metallurgical Transactions $A, 1991,22 \mathrm{~A}(2), 543-555$

7. Gold Technology, '990 Gold', Gold Technology, 1992, 6(May), 2-12

8. D.M. Jacobson \& G. Humpston, 'Gold Coatings for Fluxless Soldering', Gold Bull., 1989, 22(1), 9-17

9. H. Okamoto \& T.B. Massalski, 'The Au-Sn (GoldTin) System', Bulletin of Alloy Phase Diagrams, 1984, 5(5), 492-502

10. R.N. Wild, 'Effect of Gold on the Properties of Solders', Report No. 67-825-2157, IBM Federal Systems Division, 1968

11. D.S. Evans \& S.G. Denner, 'An Apparatus for the Determination of Solid/liquid Metal Interactions under Controlled Conditions', Practical Metallography, 1978, 15, 486-493
12. R.J. Klein Wassink, Soldering in Electronics, Electrochemical Publications Limited, 1989

13. I. Baker \& E.P. George, 'Intermetallic Compounds: An Update', Metals and Materials, 1992, 8(6), 318-323

14. C.C. Lee \& C.Y. Wang, 'A Low Temperature Bonding Process Using Deposited Gold-tin Composites', Thin Solid Films, 1992, 208, 202-209

15. G.S. Matijasevic, C.C. Lee \& C.Y. Wang, 'Au-Sn Alloy Phase Diagram and Properties Related to its Use as a Bonding Medium', Thin Solid Films, 1993 , 223, 276-287

16. Aurum, 'Gold Alloy Data: Au 750-Ag 125-Cu 125', 1980, Aurum, 1, 22-25

17. W.S. Rapson, 'The Metallurgy of the Coloured Carat Gold Alloys', Gold Bull., 1990, 23(4), 125133

18. H. Hieber et al., 'Heat Resistant Contacts with Use of Liquid Phase Transition', Proc. Conf. 7th European Hybrid Microelectronic Conference, Hamburg, 1989, May, Session 1.4

19. ITRI (undated), International Tin Research Institute, Solder Alloy Data, Publication number 656

20. P.T. Vianco, F.M. Hosking \& J.A. Rejent, 'Solderability Testing of Kovar with $60 \mathrm{Sn}-40 \mathrm{~Pb}$ Solder and Organic Fluxes', Welding Journal, 1990, 6, 230s-240s

21. R.J. Schwensfeir et al., "Comparison of Bond in Roll-bonded and Adhesively Bonded Aluminium', Proc. Symp. Welding, Bonding and Fastening, Hampton, USA, 1984, 23-25 October 1984

22. G. Humpston, D.M. Jacobson \& S.P.S. Sangha, 'A New Low Temperature Process for Joining 18 Carat Gold', Gold Technology, 1993, 9(May), 4-7 